\title{
Autonomy in consumer choice
}

Check for updates

Klaus Wertenbroch ${ }^{1} \cdot$ Rom Y. Schrift ${ }^{2}$ - Joseph W. Alba ${ }^{3}$ - Alixandra Barasch ${ }^{4}$. Amit Bhattacharjee ${ }^{5}$. Markus Giesler ${ }^{6}$. Joshua Knobe ${ }^{7}$. Donald R. Lehmann ${ }^{8}$. Sandra Matz ${ }^{8}$. Gideon Nave ${ }^{9}$. Jeffrey R. Parker ${ }^{10}$. Stefano Puntoni ${ }^{11}$. Yanmei Zheng ${ }^{12}$. Yonat Zwebner ${ }^{13}$

Published online: 8 June 2020

(C) Springer Science+Business Media, LLC, part of Springer Nature 2020

\begin{abstract}
We propose that autonomy is a crucial aspect of consumer choice. We offer a definition that situates autonomy among related constructs in philosophy and psychology, contrast actual with perceived autonomy in consumer contexts, examine the resilience of perceived autonomy, and sketch out an agenda for research into the role of perceived autonomy in an evolving marketplace increasingly characterized by automation.
\end{abstract}

Keywords Autonomy $\cdot$ Free will $\cdot$ Self-determination $\cdot$ Consumer choice $\cdot$ Marketing automation

\section{Why study consumer autonomy?}

Individual autonomy and free will are central to Western Enlightenment thinking and provide the foundation of the economic theory of consumer choice. Consumers exercise autonomy whenever they freely choose from a set of possible options, though their autonomy is inevitably subject to constraints (e.g., price, time, information). The processes by which consumers navigate these constraints are some of the primary topics of consumer research. Understanding how consumers perceive autonomy as they make these choices may be equally crucial yet understudied. We call marketing scholars' attention to studying consumer perceptions of autonomy and outline an agenda for doing so in a changing marketplace.

Technological advances are sensitizing popular discourse to novel threats to autonomy (e.g., the Cambridge Analytica scandal in 2018). Machine learning, artificial intelligence, algorithm-based personalization, and neuroscience are reshaping marketing practice, with profound implications for the nature and role of consumer autonomy (André et al. 2018). Policy makers, too, increasingly take note, shown by new measures

Klaus Wertenbroch

klaus.wertenbroch@insead.edu

Extended author information available on the last page of the article 
to safeguard consumer privacy and debates about redesigning choice environments to nudge consumers towards better decisions (Thaler and Sunstein 2008), yet discussions of these concerns and policy measures have largely occurred outside the marketing literature (Sunstein 2016; Wertenbroch 2016) or fallen outside the scope of earlier dialogues on the effects of marketing automation (Wathieu et al. 2002).

Rapid advancements in the ability to track, monitor, recommend, and predict consumers' choices, and to create novel varieties of human-machine interaction, suggest that marketing researchers renew their efforts to systematically study consumer autonomy. To that end, we offer a definition of autonomy and highlight the importance and resilience of perceived (contrasted with actual) autonomy as a worthwhile focus of consumer research to help researchers conceptualize, understand, and study autonomy in consumer choice. We close with a research agenda on the role of perceived autonomy in the changing marketplace.

\section{What is consumer autonomy?}

Different disciplines have discussed various constructs related to autonomy. We treat these constructs as sufficiently overlapping to use them interchangeably. The discipline that has most extensively dealt with autonomy is philosophy, as part of the intractable debate about what is required for an agent to have free will. Some suggest that free will requires the ability to "choose otherwise" (Kane 2011). Others argue that free will implies a particular structure of psychological states, spelled out in terms of secondorder preferences over first-order preferences or desires (Frankfurt 1971). Until recently, this debate has not been empirically informed by lay conceptions of free will.

Within the empirical literature, psychologists have weighed in on this debate with findings either denying or affirming the existence of free will as a form of volition that evolved from simpler animal agency (Baumeister and Monroe 2014; Wegner 2002). Others have noted that rather than trying to empirically determine whether free will exists, it is useful to study free-will perceptions and beliefs (Feldman 2017; Wertenbroch et al. 2008) and to explore the role of perceived autonomy, free will, and self-determination as fundamental drivers of motivation (Ryan and Deci 2000).

Within consumer choice contexts, we define autonomy as consumers' ability to make and enact decisions on their own, free from external influences imposed by other agents. As such, threats to autonomy are often localized and related to specific choices and do not challenge general beliefs about free will (Zwebner and Schrift 2020). Nonetheless, this definition is consistent with laypeople's understanding of free will as choosing and acting on one's own volition without external influence (Bandura 1989; Baumeister and Monroe 2014). It also acknowledges recent perspectives in experimental philosophy that focus on how laypeople understand free will rather than on whether it can and does exist (Nichols and Knobe 2007). People's subjective experience of autonomy may be nuanced and vary in salience and intensity.

Consistent with prior research, we distinguish autonomy from perceived control, efficacy, or competence (Ryan and Deci 2000). Control relates to consumers' ability to influence outcomes through their actions and choices; autonomy relates to consumers' freedom in initiating behavior regardless of their ability to impact the outcome (Skinner 1996). For example, while a consumer has no control over the random outcome of a 
gamble, they can make an autonomous choice to play it. Thus, the ability to freely and independently choose a desired option, regardless of one's control over the outcome of that option, distinguishes autonomy from control, and implies that autonomy is a necessary condition for perceived control but not vice versa. Note that while prior research has frequently employed choice (or the lack of it) as an experimental manipulation of control, it has often done so by hindering autonomy (a necessary condition for control). This further illustrates the distinction between autonomy and control: even in the face of uncontrollable outcome-uncertainty, consumers' desire to choose free from external influence is a fundamental and distinct driver of behavior.

\section{Actual versus perceived autonomy in consumer contexts}

Adopting this definition of autonomy, we note that marketing actions not only affect actual but also - psychologically more crucially - perceived autonomy. Actual autonomy is the extent to which a person can make and enact their own decisions. Such autonomous decision-making relies on both deliberate (system 2) and automatic (system 1) thought processes, even though the person may not be aware of the operation of these automatic processes (Kahneman 2011). Judgmental biases arising from the operation of system 1 may violate norms of rationality, but they do not necessarily undermine autonomy; they are simply part and parcel of everyday decisionmaking. Autonomy is limited by external influence (e.g., coercion, manipulation, time and resource constraints, available options, laws/regulations, social pressure).

Perceived autonomy is the individual's subjective sense of being able to make and enact decisions of their own volition. For consumers, the subjective experience of autonomy may be associated with the deliberate and effortful cognitive processes that characterize system 2 (Baumeister and Monroe 2014), yet it may become particularly pronounced when automatic and deliberate processes conflict, as when someone experiences an impulse to act (system 1) and an intention to resist it (system 2) during a self-control or moral conflict (Wertenbroch et al. 2008). ${ }^{1}$ Such conflicts often highlight the need for conscious decision-making, and are therefore, likely to increase perceived autonomy. Conversely, threats to perceived (and actual) autonomy may also involve both types of processes. System 2 may consciously respond to an external constraint such as the unavailability of a choice option, respond to accountability and justification requirements, and engage in forced deliberation or strategic impression management. External influence on system 1 may be more difficult to notice and, one could argue, constitutes a greater threat to actual than to perceived autonomy (e.g., decision frames and default nudges; Thaler and Sunstein 2008).

We propose that perceived autonomy and the ways it is threatened, maintained, or enhanced are fundamental to consumer behavior and merits researchers' and practitioners' attention in contemporary marketplace contexts. The internet has massively reduced search and transaction costs. Consumers can obtain choice options at a fraction of the cost they had to incur just several years ago. Thus, actual autonomy - in the sense of reduced constraints on consumer choice - has dramatically increased, yet when confronted with too many options, consumers may find it difficult to choose

\footnotetext{
${ }^{1}$ Kant viewed autonomy as the capacity to freely pursue objective morality rather than desire.
} 
and end up less satisfied with their choices (Botti and Iyengar 2006). This "paradox of choice" suggests that actual and perceived autonomy may not always correspond (Markus and Schwartz 2010; Schwartz 2004).

To mitigate choice overload, companies have introduced recommendation algorithms and targeting approaches that help consumers find the products and information they prefer. While such algorithms facilitate choosing and may thus boost perceived autonomy, they also run the risk of undermining actual autonomy, producing yet another paradox.

First, as more and more data accumulate on individuals' behavior and preferences, consumers become more vulnerable to covert influences on their decisions (Susser et al. 2018). Consumers may relinquish small amounts of private data in order to gain perceived autonomy (e.g., submitting a Google search query to obtain useful information), but thereby grow incrementally more susceptible to manipulations that exploit their data and undermine their actual autonomy - akin to the fabled frog being slowly boiled alive without noticing it.

Second, algorithmic microtargeting uses consumers' past behavior and choices as the basis for predicting their future preferences and serving them preferred content. As such, it reinforces existing preferences without exposing consumers to other available offerings and binds them to social networks with convergent preferences (i.e., neglecting exploration in favor of exploitation). By generating such self-reinforcing loops (Grafanaki 2017), marketing automation may gradually undermine and erode consumers' actual (and perhaps also perceived) autonomy. Consumers become less likely to be exposed to options and content that does not correspond to their revealed (first-order) preferences, depriving them of opportunities to change these preferences and choose something else (enacting their second-order preferences).

\section{Resilience of perceived autonomy}

Consumers seem to exhibit a fundamental need for autonomy: evidence of external influence on behavior need not undermine perceived autonomy (Nahmias et al. 2005), and perceived (or at least reported) autonomy remains resilient in the face of numerous threats (Rose, Buckwalter and Nicholas 2017; Zheng et al. 2016). In fact, people act to reinforce their sense of free will when it is threatened (Bear and Knobe 2016). For example, upon learning that their impending choices are predictable from their previously measured preferences, participants choose options that they prefer less in order to assert their sense of autonomy. In contrast, when being predictable is merely framed as having consistent preferences (without implying a deterministic world that impedes autonomy), there is no threat to perceived autonomy and consumers more sensibly choose their preferred options (Schrift et al. 2019).

An important determinant of perceived autonomy is whether external influence is framed abstractly or concretely (Nichols and Knobe 2007). In an abstract framing, human decisions are described as being determined (and perfectly predicted) by prior events in general. In a concrete framing, one specific decision of one specific agent is described as completely caused by prior events and thus perfectly predictable. Responding to an abstract frame, people tend to report that autonomy is undermined if human actions are completely determined, yet they tend to believe that autonomy can still be maintained 
when asked about a concrete individual action that is fully determined. Controversy remains about how to best explain this effect (Murray and Nahmias 2014).

A second factor is whether autonomy is conceptualized as psychological or biological. Previous consumer research has largely examined an important element of autonomy, self-control, through a psychological lens, involving operation by system 2 , but research elsewhere is increasingly identifying biological antecedents of willpower and self-control (Sapolsky 2017). Lay conceptions likely align with the psychological over the physical view, partly because the former is more intuitive and partly because people have a strong affinity for mind-body dualism. Physical causation can be dismissed by a coincident belief in a noncorporeal mind or soul (Bloom 2004).

A key question going forward is whether the evidence being amassed in the biological sciences will eventually alter lay beliefs. Recent research has explored this question by presenting laypeople with compelling physical evidence for failures of willpower and measuring the perceived threat to autonomy (Zheng and Alba 2019): on the whole, dualistic reasoning appears common. Despite neurological evidence to the contrary, laypeople believe that transgressors' failures of willpower can be attributed to their noncorporeal selves, especially when a transgression is morally tinged and is committed after some deliberation. They also discount the effects of a neurological deficit on their own vulnerability to transgress, again based on their own noncorporeal virtue.

The policy and practice implications of biological causation are sizeable. The prevalence and individual and societal costs of obesity and addiction continue to increase, yet policy and practice remain fractious. Interventions based on biological causation often compete with those that emphasize the primacy of willpower, perhaps reflecting conflicting underlying beliefs about autonomy. An open question is whether evidence of physical causation will alter the beliefs of policymakers, practitioners, and organizations devoted to the advancement of human welfare. These stakeholders may be swayed by the evolving beliefs of the lay public. While perceptions of autonomy in specific circumstances seem remarkably impervious to evidence of physical causation from neuroscience and genetics, it will be important for marketers to examine how consumers' experiences with new technologies in a changing marketplace affect autonomy perceptions.

\section{Perceived autonomy in a changing marketplace: a research agenda}

Providing a comprehensive account of all the research that can be meaningfully examined through the lens of autonomy is beyond the scope of this article. Instead, we highlight open questions related to consumer autonomy in marketplace contexts that are being dramatically reshaped by new technologies. Understanding how these technologies promote versus threaten consumer autonomy, with their attendant benefits and downsides, is the subject of intense and ongoing societal debates (Harari 2018). We build on the issues discussed above to outline a research agenda centered around the antecedents and consequences of consumers' perceptions of autonomy in a rapidly changing marketplace (Table 1).

Choice abundance Global supply chains and online retail offer consumers a proliferation of choice options that was unimaginable a generation ago. Lifting external 
Table 1 An agenda for research on perceived autonomy in a changing marketplace

\begin{tabular}{|c|c|c|}
\hline & $\begin{array}{l}\text { Antecedents of perceived autonomy } \\
\text { (as a dependent variable: } X \rightarrow \text { perceived } \\
\text { autonomy) }\end{array}$ & $\begin{array}{l}\text { Consequences of perceived autonomy (as a } \\
\text { mediating variable: } X \rightarrow \text { perceived } \\
\text { autonomy } \rightarrow Y \text { ) }\end{array}$ \\
\hline Choice abundance & $\begin{array}{l}\text { - Decreased search and transaction costs } \\
\text { - Increased decision difficulty, } \\
\text { complexity, preference uncertainty }\end{array}$ & $\begin{array}{l}\text { - Well-being, satisfaction } \\
\text { - Choice deferral, delegation }\end{array}$ \\
\hline $\begin{array}{l}\text { Digital choice } \\
\text { architecture and } \\
\text { decision aids }\end{array}$ & $\begin{array}{l}\text { - Decision aids (e.g., algorithms, } \\
\text { recommendation systems) } \\
\text { - Co-creation and design tools } \\
\text { - Robots and virtual assistants } \\
\text { - Personalized nudges }\end{array}$ & $\begin{array}{l}\text { - Technology adoption, driven by } \\
\text { - expertise, identity-relevance } \\
\text { - autonomy enhancement } \\
\text { - privacy invasiveness } \\
\text { - Decision quality, well-being, satisfaction }\end{array}$ \\
\hline $\begin{array}{l}\text { Marketplace } \\
\text { information and } \\
\text { transparency }\end{array}$ & $\begin{array}{l}\text { - Accumulation of customer data on own } \\
\text { and others' characteristics, behaviors, } \\
\text { preferences } \\
\text { - Privacy violations } \\
\text { - Explainability of algorithms }\end{array}$ & $\begin{array}{l}\text { - Reactions to microtargeting, intrusive } \\
\text { advertising, sophisticated persuasion } \\
\text { attempts } \\
\text { - Preference reversals under perceived } \\
\text { autonomy threat }\end{array}$ \\
\hline
\end{tabular}

constraints on what can be chosen, this choice abundance increases actual autonomy. Larger choice sets allow consumers to find products and services that more closely match their preferences (Lancaster 1990). It is an open question, though, whether online choice abundance also increases perceived autonomy. People view choice as essential to autonomy, albeit with some variation within and across cultures (Markus and Schwartz 2010). Choice boosts intrinsic motivation, perceived control, and evaluations of chosen alternatives, all improving consumer well-being (Botti and Iyengar 2006), yet expanding choice sets may increase decision difficulty, decision complexity, and preference uncertainty (Chernev et al. 2015). This raises the question whether choice abundance may, paradoxically, dampen perceived autonomy, if consumers feel externally constrained by the debilitating decision difficulty induced by choice abundance (Markus and Schwartz 2010; Novemsky et al. 2007). ${ }^{2}$

What might be possible consequences of changes in perceived autonomy from choice abundance? Lowered autonomy perceptions may mediate well-documented context and task effects on choice deferral and suboptimal choices (Dhar 1997). On the other hand, heightened autonomy perceptions may mediate consumers' ability to "choose otherwise" and change their preferences (Parker and Schrift 2011), an important means of exercising perceived autonomy. Consumers may also seek to complicate important decisions that feel too easy (Schrift et al. 2011) or relinquish what they may perceive as excessive autonomy and responsibility by avoiding or delegating difficult decisions (Markus and Schwarz 2010; Steffel and Williams 2018).

Digital choice architecture and decision aids Of course, these same advances have also inspired the development of new tools to help consumers navigate all these choices. Consumers now have a variety of algorithms, recommendation systems, search tools,

\footnotetext{
${ }^{2}$ How decision difficulty in general, triggered by factors such as type of conflict, tradeoff size and intensity, and disfluency, impacts perceived autonomy is still unexplored.
} 
personalized nudges, or voice-activated assistants at their disposal. These may increase perceptions of autonomy by enabling consumers to make better choices and enact their preferences (Logg et al. 2019). At the same time, they may introduce new ways to undermine it. Consumers often find computerized decision aids aversive, even when they promote better decisions (Dietvorst et al. 2015). Similarly, decision aids and algorithms that make consumers feel observed may decrease consumers' perceived autonomy and systematically bias their choices (Zwebner and Schrift 2020). Researchers are just the beginning to explore conditions that promote perceived autonomy and well-being in this new digital landscape, such as allowing individuals to modify algorithms or using technology to facilitate crowdsourcing and co-creation (Fuchs and Schreier 2011).

In turn, consumers' perceived autonomy may also affect the adoption of decision aids. On the one hand, household robots and virtual assistants may greatly enhance autonomy perceptions (e.g., for the elderly). Yet when consumers derive identityrelevant benefits from consuming a product, they are motivated to attribute consumption outcomes to themselves and are thus more resistant to adopt automated product features and technological assistance that undermine those attributions (Leung et al. 2018). Consistent with those findings, experienced professionals may avoid algorithmic assistance more than non-experts (Logg et al. 2019). The conceptual links between perceived autonomy and the (self-)signaling value of technology adoption call for further examination. Moreover, consumers may reject tools, which violate their privacy and undermine their perceived autonomy (Carmon et al. 2019).

Marketplace information and transparency The marketplace is replete with attempts to influence consumers. Given the self-interested nature of firms, consumers may view commercial persuasion as inherently threatening to their autonomy, even as they engage in voluntary exchanges with firms (Sunstein 2016). Armed with more and more data, firms can micro-target consumers based on their own past choices and unique characteristics, posing new challenges to consumer autonomy from privacy violations and lack of explainability (Kim et al. 2019). At the same time, consumers are better informed and more aware of their susceptibility to covert influences (Susser et al. 2018). It will be important to examine the implications of this increased transparency, which sorts of promotional practices are more threatening to perceived autonomy, and how consumers weigh these threats against the benefits of greater personalization.

A variety of consumer behaviors can be viewed as reactance to marketing actions that endanger consumers' sense of autonomy (Clee and Wicklund 1980). Privacy is a precursor of perceived autonomy (Carmon et al. 2019), and research suggests that consumers forego utility to cope with privacy-based autonomy threats. For instance, consumers often reject microtargeting and intrusive advertising practices (Goldfarb and Tucker 2011) and make choices contrary to their own preferences to assert their autonomy (Fitzsimons and Lehmann 2004; Schrift et al. 2019). Advertisements that explicitly categorize consumers may reduce their perceived autonomy in identity expression, leading them to avoid products they would otherwise prefer (Bhattacharjee et al. 2014). Future research might examine how to minimize such reactance. 


\section{Summary: the centrality of autonomy}

This paper proposes that consumer autonomy is central to consumer choice. We offer a definition that situates autonomy among related constructs in philosophy and psychology, contrast actual with perceived autonomy in consumer contexts, examine the resilience of perceived autonomy, and sketch out a research agenda for an evolving marketplace increasingly characterized by automation.

Notably, we share these ideas in the midst of the global COVID-19 lockdown, the most widespread curtailment of human autonomy in history, affecting roughly half the world's population. Restrictions in movement-limiting social and family interaction, curbing workplace activity, eliminating international travel - are imposing extraordinary human tragedy, economic collapse, and psychological harm. Social and political upheaval may follow. Yet as external constraints on autonomy have tightened, firms and (sufficiently lucky) consumers are devising creative ways to push the limits of perceived autonomy while working, exercising, and socializing from home, and to substitute online for physical experiences. These unprecedented shifts in consumer autonomy might engender enduring changes in how we use technology to work, buy, consume, and interact, making the interplay between perceived autonomy and marketing automation that we have outlined all the more relevant.

Beyond marketing, the autonomy construct raises intriguing psychological and ethical questions. With autonomy defined as freedom from external influence, can consumer choice ever be considered fully autonomous, given that all choice is subject to a choice architecture (Thaler and Sunstein 2008)? Is it more appropriate to conceptualize autonomy by degree, without an upper bound? Is perceived autonomy a function of decision difficulty? Is consensual nudging autonomy-preserving (Sunstein 2016) — when consumers engage system 2 to approve external influence on system 1 ? More broadly, when and how would consumers willingly relinquish a certain degree of autonomy to gain other benefits? When might a sense of reduced autonomy benefit individuals? These and related questions are still open and may become increasingly relevant and impactful to marketing practice and theory.

\section{References}

André, Q., Carmon, Z., Wertenbroch, K., Crum, A., Frank, D. H., Goldstein, W., Huber, J. C., van Boven, L., Weber, B., \& Yang, H. (2018). Consumer choice and autonomy in the age of artificial intelligence and big data. Customer Needs and Solutions, 5(1-2), 28-37.

Bandura, A. (1989). Human agency in social cognitive theory. American Psychologist, 44(9), 1175.

Baumeister, R. F., \& Monroe, A. E. (2014). Recent research on free will: conceptualizations, beliefs, and processes. Advances in Experimental Social Psychology, 50, 1-52.

Bear, A., \& Knobe, J. (2016). What do people find incompatible with causal determinism? Cognitive Science, 40(8), 2025-2049.

Bhattacharjee, A., Berger, J., \& Menon, G. (2014). When identity marketing backfires: consumer agency in identity expression. Journal of Consumer Research, 41(2), 294-309.

Bloom, P. (2004). Descartes' Baby. New York: basic books.

Botti, S., \& Iyengar, S. S. (2006). The dark side of choice: when choice impairs social welfare. Journal of Public Policy \& Marketing, 25(1), 24-38.

Carmon, Z., Schrift, R., Wertenbroch, K., \& Yang, H. (2019). Designing AI systems that customers won't hate. December: MIT Sloan Management Review. 
Chernev, A., Böckenholt, U., \& Goodman, J. (2015). Choice overload: a conceptual review and meta-analysis. Journal of Consumer Psychology, 25(2), 333-358.

Clee, M. A., \& Wicklund, R. A. (1980). Consumer behavior and psychological reactance. Journal of Consumer Research, 6(4), 389-405.

Dhar, R. (1997). Context and task effects on choice deferral. Marketing Letters, 8, 119-130.

Dietvorst, B. J., Simmons, J. P., \& Massey, C. (2015). Algorithm aversion: people erroneously avoid algorithms after seeing them err. Journal of Experimental Psychology: General, 144(1), 114.

Feldman, G. (2017). Making sense of agency: belief in free will as a unique and important construct. Social and Personality Psychology Compass, 11, 1-15.

Fitzsimons, G. J., \& Lehmann, D. R. (2004). Reactance to recommendations: when unsolicited advice yields contrary responses. Marketing Science, 23(1), 82-94.

Frankfurt, H. G. (1971). Freedom of the will and the concept of a person. Journal of Philosophy, 68(1), 5-20.

Fuchs, C., \& Schreier, M. (2011). Customer empowerment in new product development. Journal of Product Innovation Management, 28(1), 17-32.

Goldfarb, A., \& Tucker, C. (2011). Online display advertising: targeting and obtrusiveness. Marketing Science, 30(May), 389-404.

Grafanaki, S. (2017). Autonomy challenges in the age of big data. Fordham Intellectual Property, Media and Entertainment Law Journal, 27(4), 803-868.

Harari, Y. N. (2018), 21 lessons for the 21st century, New York: random house.

Kahneman, D. (2011). Thinking, fast and slow. New York: Farrar, Straus \& Giroux.

Kane, R. (2011). The Oxford handbook of free will. New York: Oxford University Press.

Kim, T., Barasz, K., \& John, L. K. (2019). Why am I seeing this ad? The effect of ad transparency on ad effectiveness. Journal of Consumer Research, 45(5), 906-932.

Lancaster, K. (1990). The economics of product variety: a survey. Marketing Science, 9(3), 189-206.

Leung, E., Paolacci, G., \& Puntoni, S. (2018). Man versus machine: resisting automation in identity-based consumer behavior. Journal of Marketing Research, 55(6), 818-831.

Logg, J. M., Minson, J. A., \& Moore, D. A. (2019). Algorithm appreciation: people prefer algorithmic to human judgment. Organizational Behavior and Human Decision Processes, 151, 90-103.

Markus, H. R., \& Schwartz, B. (2010). Does choice mean freedom and well-being?. Journal of Consumer Research, 37(2), 344-355.

Murray, D., \& Nahmias, E. (2014). Explaining away incompatibilist intuitions. Philosophy and Phenomenological Research, 88(2), $434-467$.

Nahmias, E., Morris, S., Nadelhoffer, T., \& Turner, J. (2005). Surveying freedom: folk intuitions about free will and moral responsibility. Philosophical Psychology, 18(5), 561-584.

Nichols, S., \& Knobe, J. (2007). Moral responsibility and determinism: the cognitive science of folk intuitions. Nous, 41(4), 663-685.

Novemsky, N., Dhar, R., Schwarz, N., \& Simonson, I. (2007). Preference fluency and consumer choice. Journal of Marketing Research, 44, 347-356.

Parker, J. R., \& Schrift, R. Y. (2011). Rejectable choice sets: how seemingly irrelevant no-choice options affect consumer decision processes. Journal of Marketing Research, 48(5), 840-854.

Rose, D., Buckwalter, W., \& Nichols, S. (2017). Neuroscientific prediction and the intrusion of intuitive metaphysics. Cognitive Science, 41(2), 482-502.

Ryan, R. M., \& Deci, E. L. (2000). Self-determination theory and the facilitation of intrinsic motivation, social development, and well-being. American Psychologist, 55, 68-78.

Sapolsky, R. M. (2017). Behave: The biology of humans at our best and worst. New York: Penguin.

Schrift, R. Y., Netzer, O., \& Kivetz, R. (2011). Complicating choice. Journal of Marketing Research, 48(2), 308-326.

Schrift, R. Y., Wertenbroch, K., \& Zwebner, Y. (2019). The dark side of microtargeting: predicting consumers' preferences threatens their sense of free will. In: R.Bagchi, L. Block, \& L. Lee (Eds.). NA Advances in Consumer Research (47) Duluth, MN : Association for Consumer Research, Pages: 254 258.

Schwartz, B. (2004). The Paradox of choice: why more is less. New York: Ecco.

Skinner, E. A. (1996). A guide to constructs of control. Journal of Personality and Social Psychology, 71(3), 549.

Steffel, M., \& Williams, E. F. (2018). Delegating decisions: recruiting others to make choices we might regret. Journal of Consumer Research, 44(5), 1015-1032.

Sunstein, C. R. (2016). Fifty shades of manipulation. Journal of Marketing Behavior, 1(3-4), 213-244.

Susser, D., Roessler, B., \& Nissenbaum, H. (2018). Online manipulation: hidden influences in a digital world. Available at SSRN 3306006. 
Thaler, R. H., \& Sunstein, C. R. (2008). Nudge: improving decisions about health, wealth, and happiness. New Haven: Yale University Press.

Wathieu, L., Brenner, L., Carmon, Z., Chattopadhyay, A., Wertenbroch, K., Drolet, A., Gourville, J., Muthukrishnan, A. V., Novemsky, N., Ratner, R., \& Wu, G. (2002). Consumer control and empowerment: a primer. Marketing Letters, 13(August), 297-305.

Wegner, D. M. (2002). The illusion of conscious will. Cambridge: MIT Press.

Wertenbroch, K. (2016). From the editor: Manipulation and marketing: the elephant in the room? Journal of Marketing Behavior, 1(3-4), 210-213.

Wertenbroch, K., Vosgerau, J., \& Bruyneel, S. (2008). Free will, temptation, and self-control: we must believe in free will, we have no choice (Isaac B. Singer). Journal of Consumer Psychology, 18(1), 27-33.

Zheng, Y., \& Alba, J.W. (2019). Mental models of the tempted mind: Implications for consumer well-being, social equality, national prosperity, and a better world. Working paper.

Zheng, Y., van Osselaer, S. M. J., \& Alba, J. W. (2016). Belief in free will: implications for practice and policy. Journal of Marketing Research, 53(6), 1050-1064.

Zwebner \& Schrift, R. Y. (2020). On my own: the aversion to being observed during the preferenceconstruction stage. Journal of Consumer Research. https://doi.org/10.1093/jcr/ucaa016.

Publisher's note Springer Nature remains neutral with regard to jurisdictional claims in published maps and institutional affiliations.

\section{Affiliations}

Klaus Wertenbroch ${ }^{1} \cdot$ Rom Y. Schrift ${ }^{2} \cdot$ Joseph W. Alba ${ }^{3} \cdot$ Alixandra Barasch $^{4}$. Amit Bhattacharjee ${ }^{5}$. Markus Giesler ${ }^{6}$. Joshua Knobe ${ }^{7}$. Donald R. Lehmann ${ }^{8}$. Sandra Matz ${ }^{8}$. Gideon Nave ${ }^{9}$. Jeffrey R. Parker ${ }^{10}$. Stefano Puntoni ${ }^{11}$ • Yanmei Zheng $^{12} \cdot$ Yonat Zwebner ${ }^{13}$

Rom Y. Schrift

rschrift@iu.edu

Joseph W. Alba

joe.alba@warrington.ufl.edu

Alixandra Barasch

abarasch@stern.nyu.edu

Amit Bhattacharjee

amit.bhattacharjee@insead.edu

Markus Giesler

mgiesler@schulich.yorku.ca

Joshua Knobe

joshua.knobe@yale.edu

Donald R. Lehmann

dr12@columbia.edu

Sandra Matz

sm4409@gsb.columbia.edu

Gideon Nave

gidi.nave@gmail.com

Jeffrey R. Parker

jeff@uic.edu 
Stefano Puntoni

spuntoni@rsm.nl

Yanmei Zheng

yanmeiz@hawaii.edu

Yonat Zwebner

zwebner.yonat@idc.ac.il

1 INSEAD, Singapore, Singapore

2 Kelley School of Business, Indiana University, Bloomington, IN, USA

3 Warrington College of Business, University of Florida, Gainesville, FL, USA

4 Stern School of Business, New York University, New York, NY, USA

5 INSEAD, Fontainebleau, France

6 Schulich School of Business, York University, Toronto, ON, Canada

7 Departments of Philosophy and Psychology, Yale University, New Haven, CT, USA

8 Columbia Business School, Columbia University, New York, NY, USA

9 The Wharton School, University of Pennsylvania, Philadelphia, PA, USA

10 Department of Managerial Studies, University of Illinois at Chicago, Chicago, IL, USA

11 Rotterdam School of Management, Erasmus University, Rotterdam, The Netherlands

12 The Shidler College of Business, University of Hawaii, Honolulu, HI, USA

13 Arison School of Business, Interdisciplinary Center Herzliya, Herzliya, Israel 